\title{
Correction
}

\section{Correction to: High Temperature Mechanical Properties of High Strength Structural Steels Q550, Q690 and Q890}

Lei Huang, Guo-Qiang Li*, Xin-Xin Wang and Chao Zhang, College of Civil Engineering, Tongji University, Shanghai, China

Guo-Qiang Li, State Key Laboratory for Disaster Reduction in Civil

Engineering, Tongji University, Shanghai, China

Chao Zhang and Lisa Choe, Fire Research Division, National Institute of

Standards and Technology, Gaithersburg, USA

Michael Engelhardt, Department of Civil, Architectural and Environmental

Engineering, University of Texas at Austin, Austin, USA

\section{Correction to: Fire Technology}

htps://doi.org/ 10.1007 /s $10694-01$ 8-0760-9

The original version of this article unfortunately contained a mistake in "Equation 1b" under Sect. 4.1. The correct equation is given below:

$$
\sigma=f_{y, T}+\left(k_{3}-k_{4} f_{y, 20}\right) \exp \left[-\left(\frac{T}{k_{2}}\right)^{k_{1}}\right]\left(\varepsilon-\frac{f_{y, T}}{E_{T}}\right)^{n} \quad\left(\varepsilon>\frac{f_{y, T}}{E_{T}}\right)
$$

\footnotetext{
* Correspondence should be addressed to: Guo-Qiang Li, E-mail: gqli@tongji.edu.cn

The original article can be found online at https://doi.org/10.1007/s10694-018-0760-9.
}

Publisher's Note Springer Nature remains neutral with regard to jurisdictional claims in published maps and institutional affiliations. 